\title{
Inovasi dan Daya Saing UMKM di Era New Normal: dari Triple Helix Model ke Quadruple Helix Model
}

\author{
Umu Khouroh $^{1 *}$, Christina Sri Ratnaningsih', Bayu Rahayudi ${ }^{2}$ \\ ${ }^{1}$ Universitas Merdeka Malang, Malang, Indonesia \\ ${ }^{2}$ Universitas Brawijaya Malang, Malang, Indonesia \\ *umu.khouroh@unmer.ac.id
}

\begin{abstract}
The role of MSMEs in the economic development of a country has important implications for increasing income, reducing unemployment, alleviating poverty and economic growth. The Covid-19 pandemic has had a negative impact and threatened the survival of MSMEs. This study aims to analyze the dynamics of the triple helix model by examining the role of each helix: universities, companies, and governments to help MSMEs rise from adversity. This study identifies behavioral profiles in terms of the performance of the triple helix model from the perspective of MSMEs and recognizes key factors for innovation success and competitiveness. The survey involved 134 MSMEs. The analysis method uses SEM-PLS with WarpPLSO7. The results of the study indicate that there is a positive influence between the synergy of the government and academia in increasing the innovation and competitiveness of MSMEs. Innovation is able to become a mediator for the synergy of the government and academia in increasing the competitiveness of MSMEs. MSMEs need to be more active and proactive, the role of the government and academics still needs to be improved and coupled with the optimal role of other helixes, especially the community as a strategy to survive and thrive in the Covid19 pandemic situation.
\end{abstract}

Keywords: Competitiveness, Covid-19, Inovation, Quadruple Helix, Triple Helix

\section{PENDAHULUAN}

Pandemi COVID-19 telah menjadi ancaman besar bagi kelangsungan perekonomian karena tidak hanya terkait dengan tantangan pasokan modal, tetapi juga rantai pasokan dan gangguan pada updownsteam (Papadopoulos et al., 2020). Laporan dampak COVID-19 menunjukkan bahwa di zona euro PDB turun 3,8 persen dan Uni Eropa turun 3.5 persen pada kuartal pertama (Eurostat, 2020). PDB AS menyusut pada kuartal kedua sebesar 25,6 persen (PWS, 2020). Di Indonesia pertumbuhan triwulan II2020 terkontraksi 5,32 persen (BPS, 2020).

Empat sektor yang paling terguncang akibat Pandemi COVID-19 yaitu sektor rumah tangga, sektor keuangan, sektor korporasi, dan sektor Usaha Mikro, Kecil dan Menengah (UMKM). UMKM menjadi yang paling rentan karena cadangan modal yang lebih rendah, aset yang lebih sedikit, dan produktivitas yang lebih rendah daripada perusahaan besar ( OECD, 2020). Hasil kajian menunjukkan bahwa akibat COVID-19, 8,76 persen perusahaan berhenti beroperasi, 24,31 persen beroperasi dengan pengurangan kapasitas (jam kerja, mesin dan tenaga kerja). Pendapatan dunia usaha menurun 82,85 persen dengan penurunan sebesar 82,29 persen (UMB) dan 84,20 persen (UMK). Pengurangan pegawai terbesar pada industri manufaktur 52,23 persen, konstruksi 51,37 
persen serta akomodasi dan makan minum 50,52 persen (BPS, 2020). Penurunan jumlah UMKM menyebabkan penyerapan tenaga kerja berkurang karena sejauh ini menyerap 97 persen tenaga kerja. Hal ini akan berdampak pada banyaknya masyarakat kehilangan pendapatan akibat perusahaan tidak dapat membayar upah secara penuh dan PHK. Hal ini berpengaruh terhadap peningkatan pengangguran yang akan menyebabkan banyak permasalahan, seperti berkurangnya pendapatan perkapita, meningkatnya biaya sosial, dan jika dibiarkan menimbulkan ketidakstabilan sosial dan politik.

UMKM selama ini telah memberikan peran penting pembangunan ekonomi seiring dengan meningkatnya jumlah UKM di banyak negara di dunia (Dolz et al., 2019) dan telah menyumbang lebih dari 90 persen bisnis di sebagian besar negara (Kamunge et al., 2014; OECD, 2017). Di Indonesia, jumlah UMKM sebanyak 64,2juta (99,99 persen dari pelaku usaha). Penyerapan tenaga kerja sebanyak 117 juta (97 persen dari tenaga kerja dunia usaha). Kontribusi terhadap PDB sebesar 61,1 persen (Kemenkopukm, 2020). Fakta ini menjadikan UMKM memiliki implikasi luas bagi perekonomian nasional. Oleh karena itu, dampak negatif COVID-19 bagi kelangsungan hidup UMKM mengharuskan UMKM menyusun ulang strategi untuk mengakomodasi efek pandemi (Kraus et al., 2020; Rapaccini et al., 2020) dan krisis (Cucculelli \& Peruzzi, 2020; Mayr et al., 2016).

Kondisi pandemi mendorong UMKM untuk berfikir terbuka untuk hal-hal baru (Roy et al., 2018) bahkan membantu untuk mengatasi inersia organisasi dan merefleksikan kelayakan model bisnis (Ucaktürk et al., 2011). Wenzel et al. (2020) merangkum bahwa inovasi adalah strategi yang memiliki efek berkelanjutan dan dapat membuat perusahaan lebih kuat untuk masa depan. Selain itu, keterbatasan sumberdaya dan kelemahan UMKM memerlukan kolaborasi lintas sektoral untuk mengatasi tantangan besar masyarakat dan menciptakan nilai bagi berbagai pemangku kepentingan
(Al-Tabbaa et al., 2013; Clarke \& Crane, 2018). Peran mereka sangat penting dalam memahami dan mengatasi permasalahan sosial yang kompleks (Van Tulder et al., 2016), terutama selama keadaan darurat global (Simo \& Bies, 2007).

Salah satu pilihan yang muncul adalah dengan melibatkan berbagai aktor dari berbagai sektor untuk bergabung menciptakan nilai bagi berbagai pemangku kepentingan dan mengurangi tantangan besar. Oleh karena itu penelitian tentang inovasi dan daya saing dalam kerangka optimalisasi triple helix menuju quadruple helix ini menjadi penting, untuk memberikan solusi bagi permasalahan UMKM akibat COVID-19 agar dampak buruk akibat terganggunya UMKM dapat teratasi dan UMKM dapat meningkatkan kinerjanya pada masa new normal.

Triple Helix Secara konseptual didefinisikan sebagai pendekatan yang menunjukkan kemunculan inovasi muncul dari adanya hubungan timbal balik, seimbang, dan berkelanjutan antara pelaku bisnis, akademisi dan pemerintah serta bagaimana mereka bertransformasi melalui hubungan tersebut (Etzkowitz, 2014; Etzkowitz \& Viale, 2010; Leydesdorff, 2012). Selanjutnya model ini berkembang menjadi Quadruple Helix dengan penambahan media sebagai heliks ke-4 (Carayannis \& Campbell, 2010; Ivanova, 2014; Leydesdorff, 2012) kemudian berkembang lagi menjadi Penta (Quintuple) Helix (Carayannis et al., 2012; Halibas et al., 2017) dengan penambahan komunitas sebagai helix ke-5 (Awaluddin et al., 2016; Sudiana et al., 2020).

Triple Helix Model (THM) telah banyak digunakan dalam literatur yang fokus pada hubungan antara universitas, industri dan pemerintah sebagai strategi untuk mendorong dinamika inovasi. THM muncul sebagai kerangka kerja untuk analisis sistem inovasi berbasis pengetahuan, menekankan hubungan ganda dan timbal balik antara tiga aktor utama dalam proses penciptaan dan kapitalisasi pengetahuan (Lombardi et al., 2012).

THM mempertimbangkan struktur hubungan timbal balik antara universitas, 
industri dan pemerintah untuk penciptaan dan pertukaran pengetahuan untuk membantu promosi inovasi di tingkat regional atau nasional (Etzkowitz, 2002; Leydesdorff \& Etzkowitz, 1996). Dalam model pengetahuan dan inovasi ini, setiap heliks sesuai dengan fungsi tradisionalnya: universitas menyediakan peneliti kreatif, perusahaan mengubah penelitian dan kreativitas menjadi produk dan inovasi, dan pemerintah berkontribusi dengan undang-undang dan dukungan keuangan. Selain itu, satu heliks dapat memainkan peran yang lain. Interaksi dan timbal balik antara ketiga bidang tersebut merupakan elemen kunci dari proses inovasi (Etzkowitz, 2002; Laguna \& Duran-Romero, 2017).

$$
\text { Temuan penelitian mengenai }
$$
bagaimana THM memberikan kontribusi penting telah banyak dilakukan. Temuan tersebut menunjukkan bahwa terdapat hubungan positif antara UMKM dengan sektor pemerintah dan sektor industri. Kolaborasi ketiganya mampu meningkatkan kreativitas, efisiensi, inovasi dan kinerja UMKM (Brink \& Madsen, 2016; Ueasangkomsate \& Jangkot, 2017). Pengalaman interaksi antar pelaku dalam lingkaran helix ini memunculkan situasi kondusif untuk mengembangkan masyarakat berbasis pengetahuan dan mampu menjadi katalisator dalam inovasi karena mereka memberikan kontribusi pada konversi ilmu pengetahuan dan teknologi untuk kemajuan ekonomi (Etzkowitz, 2002).

Strategi Triple Helix memberikan hasil yang luar biasa dengan beragam keberhasilan dari strategi dan program pengembangan Negara Welsh (Pugh, 2014). Bagi organisasi apapun, mengembangkan budaya inovasi dan praktik disarankan untuk mencapai kemampuan inovasi tinggi (Prajogo \& Ahmed, 2006). Kemitraan dan kolaborasi yang terjalin kuat antar pemain utama akan memunculkan inovasi. Pemerintah dan akademisi dalam hal ini harus mengambil peran penting untuk mempertahankan dan mendukung inovasi, terutama berkonsentrasi mendukung ketika kondisi masa kritis aset berwujud dan tidak berwujud (Ranga \& Garzik, 2015).

Kerjasama dan beraliansi dengan heliks lain memberikan ruang untuk saling bertukar informasi, melatih keterampilan, memberikan peluang baru dan lainnya sangat penting bagi kelangsungan hidup dan keberlanjutan UMKM (Khouroh et al., 2019). Beaver \& Hutchings (2005) bahkan menunjukkan bahwa dalam kondisi "kritis" dapat menjadi alat untuk menyelesaikan permasalahan yang dihadapi bisnis dengan mengintegrasikan pelatihan dan kegiatan pengembangan sebagai keputusan dan kegiatan bisnis utama. Sinergis antar pelaku dalam helix akan memberikan manfaat dalam menumbuhkan inovasi dan memunculkan ekonomi berbasis inovasi.

Berdasarkan uraian tersebut, dirumuskan hipotesis sebagai berikut:

$\mathrm{H}_{1}$ : Kolaborasi akademisi-pemerintah mampu meningkatkan daya saing UMKM

$\mathrm{H}_{2}$ : Kolaborasi akademisi-pemerintah mampu meningkatkan inovasi UMKM

$\mathrm{H}_{3}$ : Inovasi mampu meningkatkan daya saing UMKM

$\mathrm{H}_{4}$ : Inovasi memediasi hubungan akademisipemerintah dengan daya saing UMKM

\section{METODE}

Penelitian ini menggunakan jenis penelitian eksplanasi dengan pendekatan kuantitatif dan desain analisis deskriptif. Populasi penelitian ini adalah UMKM di Kabupaten Malang. Jumlah sampel untuk keperluan analisis data sebagaimana direkomendasikan Sekaran \& Bougie (2013) berkisar 30-500 atau 100 atau lebih (Hair et al., 2017) sehingga ukuran minimal 100 sampel dianggap sudah mencukupi. Pengumpulan data melalui link survei yang dikirimkan kepada himpunan, gabungan, paguyuban, perkumpulan, jaringan asosiasi, dan bentuk komunitas lainnya. Pada akhir waktu pengumpulan data, diperoleh 134 respon.

Skala pengukuran yang digunakan skala Likert 5 poin. Metode analisis data menggunakan analisis statistik deskriptif untuk menjelaskan karakter responden dan 
deskripsi variabel penelitian. Sedangkan untuk pengujian hipotesis menggunakan metode analisis SEM-PLS guna memperoleh gambaran jelas dari keterkaitan antar variabel. Adapun kerangka penelitian ini ditunjukkan pada Gambar 1.

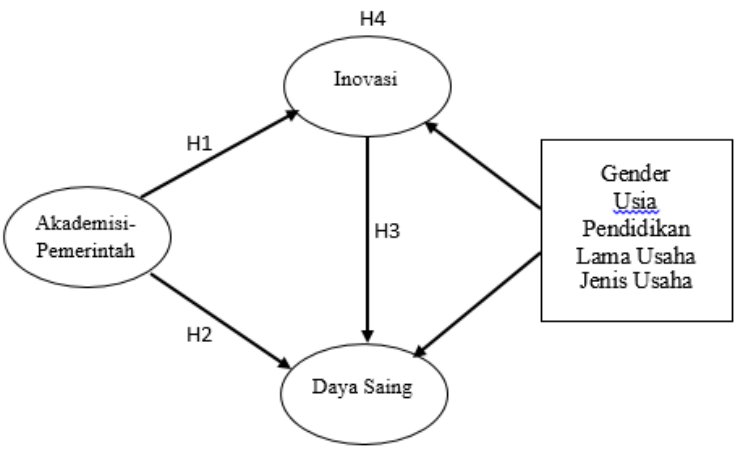

Gambar 1: Kerangka Model Penelitian

\section{HASIL DAN PEMBAHASAN Deskripsi Responden}

Karakteristik demografi dan profil usaha sebagaimana ditunjukkan pada Tabel 1 menggambarkan bahwa karakteristik responden didominasi oleh UMKM yang dikelola oleh perempuan, dengan usia responden terbanyak antara 40-49 tahun, jenjang pendidikan SMA sederajat. Dari aspek profil usaha sebagian besar menggeluti usaha kurang dari 5 tahun dengan jenis usaha terbanyak kuliner.

Tabel 1. Karakteristik Demografi dan Profil Usaha

\begin{tabular}{llrr}
\hline Karakteristik & Deskripsi & Jumlah & $\%$ \\
\hline Jenis & Laki laki & 28 & 20,9 \\
kelamin & Perempuan & 106 & 79,1 \\
Usia & $<30$ tahun & 21 & 29.67 \\
& 30-39 tahun & 42 & 27.24 \\
& 40-49 tahun & 51 & 9.35 \\
Jenjang & SD tahun & 20 & 33.74 \\
pendidikan & SMP & 13 & 9,7 \\
& SMA & 19 & 14,2 \\
& Diploma & 76 & 56,7 \\
Lama Usaha & S1 & 8 & 6 \\
& $\leq 5$ tahun & 18 & 13,4 \\
& 6- 10 tahun & 90 & 67,2 \\
& 11 -15 tahun & 14 & 10,4 \\
& $16-20$ tahun & 17 & 9,7 \\
& $>20$ tahun & 0 & 12,7 \\
Jenis usaha & Fashion & 18 & 0 \\
& Jasa & 13 & 9,4 \\
& Kerajinan & 8 & 6,0 \\
& Kuliner & 65 & 48,5 \\
& Perdagangan & 30 & 22,4 \\
\hline
\end{tabular}

\section{Deskripsi Variabel}

Hasil analisis tentang deskripsi variabel yang ditunjukkan Tabel 2 menunjukkan bahwa dukungan akademisi-pemerintah, inovasi dan daya saing UMKM memperoleh penilaian yang cukup baik dengan skor 3,63 untuk dukungan akademisi-pemerintah, 3,6 untuk inovasi dan 3,62 untuk daya saing UMKM. Hasil ini mengindikasikan masih banyak yang harus dilakukan oleh akademisipemerintah dan UMKM dalam THM ini.

Tabel 2. Deskripsi Variabel

\begin{tabular}{lcr}
\hline \multicolumn{1}{c}{ Variabel } & $\begin{array}{c}\text { Rata- } \\
\text { rata }\end{array}$ & $\begin{array}{r}\text { Standar } \\
\text { Deviasi }\end{array}$ \\
\hline Akademisi-Pemerintah & 3,63 & 1,26 \\
Inovasi & 3,60 & 1,14 \\
Daya Saing & 3,62 & 1,19 \\
\hline
\end{tabular}

\section{Pengujian Hipotesis}

Pengujian untuk model struktural dilakukan dengan mengevaluasi $\mathrm{R}^{2}$ sebagai alat ukur akurasi dari prediksi model yaitu mengukur kemampuan dari variabel eksogen dalam menjelaskan variabel endogen. Chin (1998) mengklasifikasikan batasan nilai $\mathrm{R}^{2}$ dengan kriteria 0,67 diartikan substansial; 0,33 diartikan moderat dan 0,19 diartikan lemah.

Tabel 3. Nilai $R$-Square

\begin{tabular}{lcc}
\hline \multicolumn{1}{c}{ Variabel } & $R$-Square & Keterangan \\
\hline Inovasi & 0,24 & Lemah \\
Daya Saing & 0,56 & Moderat \\
\hline
\end{tabular}

Hasil pengujian hipotesis menggunakan warpPLS 7.0 ditunjukkan pada Tabel 4. Hasil pengujian hipotesis menunjukkan bahwa dukungan akademisi-pemerintah memiliki pengaruh positif terhadap inovasi dan daya saing. Demikian juga halnya dengan inovasi yang berpengaruh positif sehingga mampu meningkat daya saing UMKM selain menjadi mediator dalam hubungan antara akademisipemerintah dan daya saing UMKM.

Tabel 4. Hasil Uji Hipotesis

\begin{tabular}{lccl}
\hline \multicolumn{1}{c}{ Jalur } & $\begin{array}{c}\text { Koefisien } \\
\text { jalur }\end{array}$ & $\begin{array}{c}P \\
\text { Values }\end{array}$ & Hasil \\
\hline $\begin{array}{l}\text { Akademisi-Pemerintah } \rightarrow \\
\text { Inovasi }\end{array}$ & 0,426 & $<0,001$ & Signifikan \\
$\begin{array}{l}\text { Akademisi-Pemerintah } \rightarrow \\
\text { Daya Saing }\end{array}$ & 0,371 & $<0,001$ & Signifikan
\end{tabular}




\begin{tabular}{lccc}
\hline \multicolumn{1}{c}{ Jalur } & $\begin{array}{c}\text { Koefisien } \\
\text { jalur }\end{array}$ & $\begin{array}{c}P \\
\text { Values }\end{array}$ & Hasil \\
\hline $\begin{array}{l}\text { Inovasi } \rightarrow \text { Daya Saing } \\
\text { Akademisi-Pemerintah } \rightarrow\end{array}$ & 0,497 & $<0,001$ & Signifikan \\
Inovasi $\rightarrow$ Daya Saing & & & Signifikan \\
\hline Variabel Kontrol & 0,212 & $<0,001$ & \\
Gender $\rightarrow$ Inovasi & $-0,024$ & 0,392 & Tidak Signifikan \\
Usia $\rightarrow$ Inovasi & 0,036 & 0,337 & Tidak Signifikan \\
Pendidikan $\rightarrow$ Inovasi & $-0,074$ & 0,193 & Tidak Signifikan \\
Lama Usaha $\rightarrow$ Inovasi & $-0,144$ & 0,043 & Signifikan \\
Jenis Usaha $\rightarrow$ Inovasi & $-0,137$ & 0,052 & Tidak Signifikan \\
Gender $\rightarrow$ Daya Saing & $-0,087$ & 0,153 & Tidak Signifikan \\
Usia $\rightarrow$ Daya Saing & $-0,032$ & 0,357 & Tidak Signifikan \\
Pendidikan $\rightarrow$ Daya Saing & 0,016 & 0,426 & Tidak Signifikan \\
Lama Usaha $\rightarrow$ Daya Saing & 0,077 & 0,182 & Tidak Signifikan \\
Jenis Usaha $\rightarrow$ Daya Saing & $-0,030$ & 0,362 & Tidak Signifikan \\
\hline
\end{tabular}

Hasil analisis menunjukkan seluruh hipotesis yang diajukan diterima. Hal ini berarti bahwa kolaborasi akademisipemerintah mampu meningkatkan daya saing UMKM. Kolaborasi akademisi-pemerintah juga mampu meningkatkan inovasi UMKM. Inovasi mampu meningkatkan daya saing UMKM dan memediasi hubungan akademisipemerintah dengan daya saing UMKM. Uji pengaruh variabel kontrol terhadap inovasi dan daya saing UMKM menunjukkan bahwa hanya lama usaha yang berpengaruh terhadap inovasi.

\section{Pembahasan}

Hasil analisis statistik menunjukkan bahwa akademisi-pemerintah memberikan dampak positif bagi kinerja inovasi dan daya saing UMKM. Hasil ini sejalan dengan temuan sebelumnya yang menunjukkan bahwa akademisi-pemerintah memiliki dampak positif dan signifikan terhadap afiliasi dan kesuksesan bisnis (Jasra et al., 2011; Khouroh et al., 2019) juga akan meningkatkan kemampuan inovasi perusahaan dan merangsang kolaborasi (Kang $\&$ Park, 2012). Studi ini memaparkan tentang peran sosial dan ekonomi masing-masing pelaku dalam THM dalam proses inovasi dan daya saing UMKM. Inovasi sangat penting dalam mencapai keunggulan kompetitif bagi UMKM. Selama dekade terakhir, model ini telah digunakan untuk meningkatkan eksplorasi dan eksploitasi pengetahuan dan untuk mempromosikan inovasi, didukung oleh beberapa penelitian mengenai keterkaitan pemerintah-industri-universitas (Leydesdorff \& Zawdie, 2010).

Model ini juga dapat digunakan untuk menjelaskan dinamika inovasi yang berbeda meskipun dari aspek gender, usia dan tingkat pendidikan tidak memberikan dampak besar bagi kinerja inovasi UMKM. UMKM yang mempunyai lama usaha yang semakin banyak ternyata kinerja inovasinya rendah. Hal ini dimungkinkan mengingat karakteristik usia responden dengan kinerja inovasi rendah didominasi oleh usia tua.

Demikian juga halnya dengan dampak dari jenis usaha terhadap kinerja inovasi yang menunjukkan bahwa jenis usaha UMKM dibidang pertanian, perdagangan, kuliner tidak membawa implikasi penting mengingat keseragaman usaha. Sebaliknya bagi jenis usaha fashion, jasa dan kerajinan, memberikan bukti dan mengukuhkan fakta bahwa jenis usaha ini memang mengharuskan UMKM untuk melakukan inovasi yang lebih banyak sehingga menjadi lebih inovatif dibanding pesaingnya. Kondisi ini mempertegas bahwa ada beberapa aspek yang harus diperhatikan seperti fakta sebagian besar UMKM berukuran mikro dan kegiatannya terkonsentrasi di sektor primer. Kegiatan-kegiatan ini kurang bernilai tambah sehingga membatasi akses ke sumber daya, teknologi dan pendanaan serta mempengaruhi dimensi dan konsentrasi bisnis.

Aspek yang sangat penting dalam hal ini adalah bobot relatif helix, yang dalam konteks ini dihasilkan dari inisiatif perguruan tinggi dan pemerintah. Kurangnya UMKM dalam hal kemampuan keuangan untuk mendukung inovasi membuat akademisipemerintah memiliki peran utama dalam mengkondisikan berfungsinya model. Kaitan ini muncul karena pendanaan untuk penelitian pada dasarnya bersifat publik, dan universitas berfungsi sebagai "pembantu" dalam Triple Helix Model (THM) di mana pemerintah bertindak sebagai mesin (Etzkowitz \& Zhou, 2007) dan heliks yang dominan (Lawton \& Bagchi-Sen, 2010).

Daya saing UMKM tidak hanya bergantung pada ketersediaan sumber daya internal, tetapi juga pada dinamika inovatifnya. Kemampuan inovatif ini meningkatkan daya tarik UMKM dalam hal bisnis baru, perusahaan baru, investasi baru, dan produk baru; secara bersamaan, ini 
menarik kaum muda dan individu dengan tingkat pendidikan tinggi. Dalam THM, keberadaan inovasi terkait dengan jaringan pelaku (Leydesdorff \& Etzkowitz, 1996) menjadi stimulator dinamika dan perkembangan bisnis.

Dalam THM, pemerintah memainkan peran yang semakin penting dalam menyediakan regulasi dan mendorong inovasi. Universitas memainkan peran inovatif dalam pengembangan UMKM. Mereka fokus pada tugas kewirausahaan, seperti menciptakan wirausaha baru, sedangkan industri berbagi pengetahuan dan melatih karyawan (Etzkowitz et al., 1998; Tuunainen, 2002) Selain peran pendidikan, mereka melakukan kegiatan penelitian, pembinaan usaha, dan pengembangan masyarakat (Etzkowitz, 2002) serta menyediakan stimulasi sosial dan ekonomi (Chaminade et al., 2007). QHM didasarkan pada kenyataan bahwa perguruan tinggi memiliki peran penting dalam pembangunan sosial dan ekonomi (Etzkowitz, 2002). Kegiatan inovasi mereka berkontribusi pada perkembangan ekonomi dan memberikan kesempatan kepada peneliti untuk mendapatkan keuntungan finansial (Leydesdorff \& Etzkowitz, 1996). Peran ini menjadi lebih penting mengingat fakta bahwa institusi secara geografis terdesentralisasi dan memiliki sifat organisasi yang lebih fleksibel. Sumber daya manusia mampu menjalankan peran yang berbeda dalam proses inovasi. Dalam perspektif evolusionis hubungan antara perusahaan, universitas, dan pemerintah fleksibel dan terus berubah seiring waktu (Coenen \& Moodysson, 2009).

THM dapat berfungsi sebagai platform dalam penciptaan institusi baru dan bentuk manajemen lain seperti pusat pengembangan bisnis, sains dan teknologi (Etzkowitz, 2002) yang di Indonesia di kenal dengan nama PLUT (Pusat Layanan Usaha Terpadu). Organisasi ini tercipta berkat kerjasama pelaku usaha/akademisi/ pemerintah dan merupakan fenomena global, karena menggabungkan dan menyesuaikan metode manajemen yang ada dengan kebutuhan UMKM untuk mendorong pengembangan ekonomi dan daya saing. Agar THM berjalan efektif, diperlukan pemahaman tentang faktor-faktor yang mempengaruhi dinamika inovasi serta adanya kerjasama antar agen kemajuan inovasi dalam THM.

THM yang diajukan, dibuat dengan tujuan untuk mendeskripsikan dan mengkarakterisasi interaksi antara helix (universitas-perusahaan-pemerintah) dalam proses inovasi dan pengembangan yang sangat dibutuhkan di situasi pandemi saat ini. Sayangnya hasil penelitian menunjukkan bahwa dalam THM dukungan akademisi dan pemerintah masih belum optimal. Kehadiran helix lain berupa komunitas menjadi salah satu solusi untuk mengatasi permasalahan tersebut. Sebagaimana dikatakan oleh Peng et al. (2008) bahwa kolaborasi menyatukan berbagai kelompok aktor yang perannya sangat vital ketika lembaga formal tidak berkembang dengan baik. Dengan demikian, pemerintah di domain ini tidak dapat menangani masalah nasional dalam masyarakat mereka sendiri, mengingat basis sumber daya dan pengetahuan mereka yang terbatas (Rao-Nicholson et al., 2017).

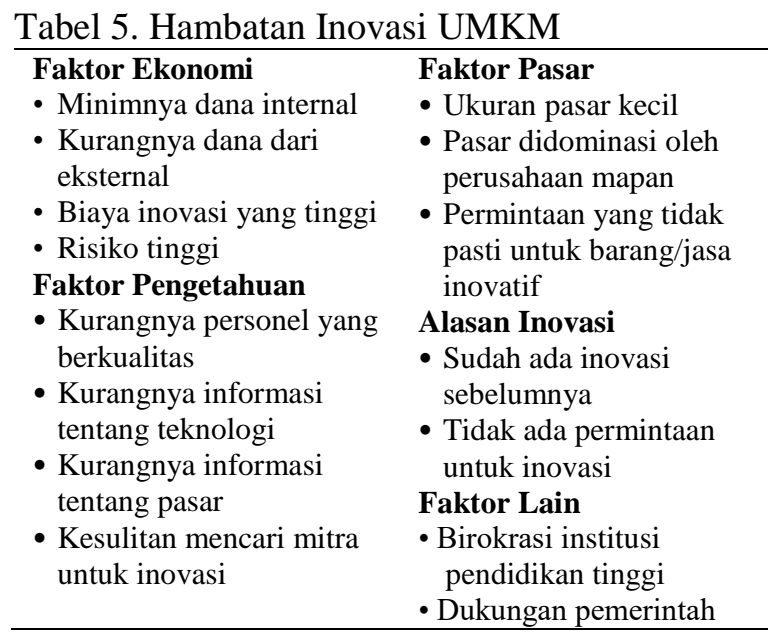

Banyak faktor yang mendasari mengapa komunitas dalam Quadruple Helix Model (QHM) memberikan peran penting dalam proses inovasi UMKM. Selama ini UMKM menghadapi permasalahan mendasar terkait dengan inovasi. Hambatan yang dihadapi UMKM dalam inovasi ditunjukkan dalam Tabel 5 yang meliputi 1) hambatan ekonomi seperti terbatasnya pendanaan 
internal maupun eksternal, inovasi yang membutuhkan biaya tinggi serta risiko tinggi akibat kemungkinan gagalnya inovasi; 2) hambatan pengetahuan seperti kurangnya personel yang berkualitas, kurangnya informasi tentang teknologi dan pasar, kesulitan mencari mitra untuk inovasi sebagai konsekuensi keterbatasan sumberdaya dan ukuran usaha yang kecil; 3) hambatan pasar akibat skala usaha yang di miliki UMKM membawa dampak pada kecilnya pasar yang bisa dicapai karena pasar produk didominasi perusahaan besar dan mapan serta ketidakpastian permintaan pada barang/jasa inovatif mengingat sifatnya yang baru sehingga belum dikenal pasar; 4) hambatan dari inovasi seperti keenganan UMKM untuk melakukan inovasi baru karena sebelumnya sudah melakukan inovasi dan pasar belum membutuhkan inovasi sehingga dorongan untuk melakukan inovasi terhambat; dan 5) hambatan birokrasi pada institusi pendidikan tinggi yang menjadi mitra menjadikan proses inovasi berjalan lambat yang membatasi ruang gerak UMKM untuk mengembangkan usaha serta dukungan pemerintah yang masih belum optimal dalam membantu pengembangan usaha dan inovasi UMKM.

Inti dari proses inovasi adalah perusahaan dan heliks lainnya serta konsep sirkulasi di QHM. Dinamisasi sistem dalam QHM mengurangi hambatan dalam interaksi dan kerjasama, meningkatkan aktivitas di dalam dan di antara lingkungan kelembagaan dan mendorong pembangunan berkelanjutan. Sirkulasi antara empat bidang berkontribusi pada dinamika inovasi yang lebih mudah dan memfasilitasi aliran individu, ide, dan inovasi. Kendala dan kesulitan dapat diminimalisir melalui interaksi dan kerjasama dengan perguruan tinggi dan komunitas yang memberikan manfaat baik bagi UMKM maupun perguruan tinggi dan komunitas. Perubahan dan interaksi antara heliks-heliks ini memungkinkan UMKM untuk mengakses sumber daya khusus dan pengetahuan baru, sementara universitas memperoleh pengetahuan praktis, sumber daya keuangan, dan fungsi sosial (Natário et al., 2012).
Penelitian Mulyaningsih (2015), Campanella et al. (2016) dan Machado et al. (2018) menunjukkan kinerja quadruple helix dengan lebih jelas. Mulyaningsih (2015) menyikapi heliks ke empat sebagai komunitas dengan peran utama mendorong proses inovasi, dengan menciptakan permintaan barang dan jasa. Penulis mengangkat dua kasus: Creative Community Association (CCA) dan Community Development Center (CDC). Dalam kasus CCA, komunitas berada di pusat heliks, dengan pemerintah dan masyarakat menjadi heliks yang dominan. Dalam kasus CDC, industri adalah sektor yang dominan, dan berperan penting membantu masyarakat. Campanella et al. (2016) mengamati bahwa heliks ini adalah variabel penjelas untuk mempertahankan pentingnya kolaborasi dengan pengguna, konsumen, dan warga negara untuk menciptakan inovasi. Akhirnya, dalam pandangan Machado et al. (2018), masyarakat berpartisipasi dalam dinamika inovasi, termasuk berbagai bentuk komersialisasi, dan semua aktor menciptakan nilai dalam ekosistem inovasi..

Interkoneksi antara heliks dan proses kerjasama untuk inovasi menguntungkan semua aktor. Manfaat tersebut bagi universitas termasuk pemenuhan fungsi sosial universitas; pengetahuan praktis tentang masalah yang ada; penggabungan pengetahuan baru untuk praktik pengajaran dan penelitian; sumber daya keuangan tambahan; akuisisi sumber daya material tambahan; prestise bagi peneliti; dan publisitas untuk universitas. Manfaat terpenting bagi UMKM termasuk akses ke orang-orang berkualifikasi tinggi dari universitas; solusi masalah teknis yang membutuhkan penelitian; pengurangan biaya dan risiko yang melibatkan proyek $R \& D$; akses ke pengetahuan yang diperoleh di bidang pendidikan; dan identifikasi siswa untuk dipekerjakan di masa depan. Sedangkan manfaat penting kehadiran UMKM dalam komunitas adalah memperluas relasi/jaringan; menambah wawasan dan keterampilan; meningkatkan kepercayaan diri; meningkatkan awareness brand bisnis; 
sumber informasi; membantu akses dan riset pasar; memberikan feedback; ajang untuk kegiatan kerjasama dan sharing peralatan/teknologi.

Dalam QHM juga menunjukkan peran pemerintah sebagai katalisator dalam mendorong keadilan yang transparan, kerjasama, dukungan logistik, dan akses informasi serta berinvestasi dalam inovasi dengan menetapkan dan mengadopsi undangundang yang mendorongnya. Pemerintah merupakan heliks penting dalam komplementaritas dunia usaha dan pendidikan untuk pembangunan dan daya saing daerah (Natário et al., 2012). Dinamika inovasi bisnis, membutuhkan hubungan yang kuat antara keempat bidang tersebut dalam bentuk kerjasama. Penting untuk menemukan pasangan yang ideal dan berbagai bentuk interkoneksi dalam ruang inovasi. Ruangruang ini dipandang sebagai penggerak kerjasama yang merangsang inovasi.

Dalam ruang lingkup hubungan antar pelaku dalam QHM, hal-hal penting yang perlu dilakukan agar QHM berjalan efektif antara lain: memunculkan wirausahawan di dunia pendidikan; kunjungan akademisi ke UMKM; UMKM yang mempromosikan inovasi dan kerjasama dengan universitas dan komunitas atau sebaliknya; duduk bersama untuk diskusi; pertemuan untuk berbagi pengetahuan; dukungan untuk perekrutan trainee; magang untuk mahasiswa dan dosen di UMKM; kemitraan untuk penelitian teknologi dan dukungan keuangan untuk mengembangkan penelitian; layanan respon cepat dengan teknologi informasi serta konsultasi teknis dan manajemen; implementasi dan pengelolaan kelompok dalam kemitraan teknologi; berbagi peralatan yang dipasok ke universitas dan komunitas oleh UMKM atau sebaliknya; kegiatan dengan alumni yang sekarang bekerja di perusahaan; penggunaan tempat untuk berbagi informasi; taman sains dan inkubator; program manajemen teknologi; program pendidikan berkelanjutan; penyuluhan dan kursus khusus; dan program pendidikanpelatihan jarak jauh.

\section{Kesimpulan}

Penelitian ini memberikan bukti empiris bahwa akademisi-pemerintah memberikan dampak positif bagi kinerja inovasi dan daya saing UMKM. Kinerja inovasi UMKM juga mampu meningkatkan daya saing sekaligus juga mampu menjembatani hubungan antara akademisipemerintah dengan daya saing UMKM. Studi ini berkontribusi untuk memahami kinerja THM dalam kinerja inovasi dan daya saing UMKM. Hubungan positif antara peran akademisi-pemerintah terhadap inovasi dan daya saing, inovasi terhadap daya saing serta kemampuan inovasi dalam memediasi hubungan akademisi-pemerintah dengan daya saing menunjukkan perlunya meningkatkan komitmen antara ketiga heliks yang dirasakan masih belum optimal. Dalam konteks ini kehadiran komunitas menjadi solusi agar memperoleh hasil optimal.

Kolaborasi merupakan metode yang baik untuk meningkatkan keterampilan inovatif dan daya saing UMKM di masa pandemi. Aspek lain dalam penerapan THM yang timbul karena hubungan dan kerjasama di bidang-bidang yang basis bisnisnya lemah dan tidak ada sumber daya yang mendasar serta tingkat spesialisasi yang sesuai, mengarah pada kebutuhan untuk membangun hubungan lain yaitu hadirnya komunitas (quadruple helix model-QHM), menjadi suatu fitur yang memungkinkan hadirnya inovasi yang lebih efektif dan optimal antara pelaku dalam helix.

Karena studi ini terbatas pada wilayah tertentu, maka hasilnya perlu disesuaikan dengan data dari wilayah lain. Selain itu, analisis yang lebih rinci tentang mekanisme mikro dari proses inovasi perlu diteliti, mungkin menggunakan pendekatan longitudinal atau studi kasus.

\section{DAFTAR PUSTAKA}

Al-Tabbaa, O., Leach, D., \& March, J. (2013). Collaboration between nonprofit and business sectors: a framework to guide strategy development for nonprofit organizations. Voluntas: International Journal of Voluntary and Nonprofit 
Organizations, 25(3), 657-678. https://doi.org/10.1007/s11266-013-9357-6

Awaluddin, M., Sule, E. T., Sucherly, \& Kaltum, U. (2016). The influence of competitive forces and value creation on company reputation and competitive strategy: a case of digital creative industry in Indonesia with the implication on sustainable business performance. International Journal of Economics, Commerce and Management, IV(2), 201-234.

Beaver, G., \& Hutchings, K. (2005). Training and developing an age diverse workforce in SMEs: The need for a strategic approach. Education and Training, 47(8/9), 592-604. https://doi.org/10.1108/0040091051063313 4

BPS. (2020a). Analisis Hasil Survey Dampak Covid-19 terhadap Pelaku Usaha.

BPS. (2020b). Berita Resmi Statistik.

Brink, T., \& Madsen, S. O. (2016). The triple helix frame for small- and medium-sized enterprises for innovation and development of offshore wind energy. A Journal of University-Industry-Government Innovation and Entrepreneurship, 3(4), 1-23.

Campanella, F., Rosaria, M., Peruta, D., Bresciani, S., \& Dezi, L. (2016). Quadruple helix and firms' performance: an empirical verification in Europe. The Journal of Technology Transfer, 42(2), 267-284. https://doi.org/10.1007/s10961-016-9500-9

Carayannis, E. G., Barth, T. D., \& Campbell, D. F. J. (2012). The quintuple helix innovation model: global warming as a challenge and driver for innovation. Journal of Innovation and Entrepreneurship, 1(1), 1-12.

Carayannis, E. G., \& Campbell, D. F. J. (2010). Triple helix, quadruple helix and quintuple helix and how do knowledge, innovation, and the environment relate to each other? International Journal of Social Ecology and Sustainable Development, 1(1), 41-69. https://doi.org/10.4018/jsesd.2010010105

Chaminade, C., Vang-Lauridsen, J., \& Coenen, L. (2007). Learning from the Bangalore experience: the role of universities in an emerging regional innovation system. CIRCLE.

Chin, W. W. (1998). The partial least squares approach for structural equation modeling. In Methodology for Business and Management. Modern methods for business research. (pp. 295-336). Mahwah, NJ, US: Lawrence Erlbaum Associates Publishers.
Clarke, A., \& Crane, A. (2018). Cross sector partnerships for systemic change: systematized literature review and agenda for further research. Journal of Business Ethics, 150(2), 303-313. https://doi.org/10.1007/s10551-018-3922-2

Coenen, L., \& Moodysson, J. (2009). Putting constructed regional advantage into Swedish practice. European Planning Studies, 17(4), 587-604.

Cucculelli, M., \& Peruzzi, V. (2020). Innovation over the industry life-cycle. Does ownership matter? Research Policy, 49(1), 103878. https://doi.org/10.1016/j.respol.2019.10387 8

Dolz, C., Iborra, M., \& Safón, V. (2019). Improving the likelihood of SME survival during financial and economic crises: the importance of TMTs and family ownership for ambidexterity. Cuadernos de Economía Y Dirección de La Empresa, 22(2), 119-136. https://doi.org/10.1016/j.brq.2018.09.004

Etzkowitz, H. (2002). The triple helix of university - industry - government relations: implications for policy and evaluation. In SE-114 28.

Etzkowitz, H. (2014). The entrepreneurial university wave: from ivory tower to global economic engine. Industry and Higher Education, 28(4), 223-232. https://doi.org/10.5367/ihe.2014.0211

Etzkowitz, H., \& Viale, R. (2010). Polyvalent knowledge and the entrepreneurial university: A third academic revolution? Critical Sociology, 36(4), 595-609. https://doi.org/10.1177/0896920510365921

Etzkowitz, H., Webster, A., \& Healey, P. (1998). Capitalizing knowledge: University intersections of industry and academia. Albany: State University of New York Press.

Etzkowitz, H., \& Zhou, C. (2007). Regional innovation initiator: the entrepreneurial university in various triple helix models. Triple Helix Conference VI in Singapore.

Eurostat. (2020). Eurostat new release.

Hair, J. F., Hult, G. T. M., Ringle, C. M., \& Sarstedt, M. (2017). A Primer on Partial Least Squares Structural Equation Modelling (PLS-SEM) ( $2^{\text {nd }} \quad$ Edition.). Thousand Oaks, California: SAGE Publications.

Halibas, A. S., Sibayan, R. O., \& Maata, R. L. R. (2017). The penta helix model of innovation in Oman: an HEI Perspective. 
Interdisciplinary Journal of Information, Knowledge, and Management, 12, 159-172.

Ivanova, I. (2014). Quadruple helix systems and symmetry: a step towards helix innovation system classification. Journal of the Knowledge Economy, 5(2), 357-369. https://doi.org/10.1007/s13132-014-0201-z

Jasra, J. M., Khan, M. A., Hunjra, A. I., Ur Rchman, R. A., \& Azam, R. I. (2011). Determinants of business success of small and medium enterprises. International Journal of Business and Social Science, 2(20), 869-872.

Kamunge, M. S., Njeru, A., \& Tirimba, O. I. (2014). Factors affecting the performance of small and micro enterprises in Limuru Town Market of Kiambu County, Kenya. International Journal of Scientific and Research Publications, 4(12), 1-20.

Kang, K. N., \& Park, H. (2012). Influence of government R\&D support and inter-firm collaborations on innovation in Korean biotechnology SMEs. Technovation, 32(1), 68-78.

Kemenkopukm, K. K. dan U. K. dan ah-M. R. I.-. (2020). Rencana strategis kementerian koperasi dan usaha kecil dan menengah tahun 2020 - 2024.

Khouroh, U., Windhyastiti, I., \& Handayani, K. (2019). Peran kebijakan pemerintah dalam memperkuat aliansi strategis dan meningkatkan daya saing ekonomi kreatif. Jurnal Manajemen Dan Kewirausahaan, 7(2), 205-224.

Kraus, S., Clauss, T., Breier, M., Gast, J., Zardini, A., \& Tiberius, V. (2020). The economics of COVID-19: initial empirical evidence on how family firms in five European countries cope with the corona crisis. International Journal of Entrepreneurial Behavior \& Research, 26(5), 1067-1092. https://doi.org/10.1108/IJEBR-04-20200214

Laguna, N. E., \& Duran-Romero, G. (2017). Science parks approaches to address sustainability: a qualitative case study of the science parks in Spain. International Journal of Social Ecology and Sustainable Development (IJSESD), 8(3), 38-55. https://doi.org/10.4018/IJSESD.201707010 3

Lawton, S. H., \& Bagchi-Sen, S. (2010). Triple helix and regional development:a perspective from Oxfordshire. Technology
Analysis \& Strategic Management, 22(7), 805-818.

Leydesdorff, L. (2012). The triple helix quadruple helix, an N-tuple helices: explanatory models for analysing the knowledge-based economy? Journal of Knowledge Economics, 3, 25-35. https://doi.org/10.1007/s13132-011-0049-4

Leydesdorff, L. (2012). The triple helix, quadruple helix, ... , and an $\mathrm{N}$-tuple of helices: explanatory models for analyzing the knowledge-based economy? Journal of the Knowledge Economy, 3(1), 25-35. https://doi.org/10.1007/s13132-011-0049-4

Leydesdorff, L., \& Etzkowitz, H. (1996). Emergence of a triple-helix of universityindustry government relations. Science and Public Policy, 23(5), 279-286.

Leydesdorff, L., \& Zawdie, G. (2010). The triple helix perspective of innovation systems. Technology Analysis \& Strategic Management, 22(7), 789-804.

Lombardi, P., Giordano, S., Farouh, H., \& Yousef, W. (2012). Modelling the smart city performance. Innovation: The European Journal of Social Science Research, 25(2), 137-149.

https://doi.org/10.1080/13511610.2012.660 325

Machado, H. V., Lazzarotti, F., \& Bencke, F. F. (2018). Innovation models and technological parks: interaction between parks and innovation agents. Journal of Technology Management \& Innovation, 13(2), 104-114.

Mayr, S., Mitter, C., \& Aichmayr, A. (2016). Corporate Crisis and Sustainable Reorganization: Evidence from Bankrupt Austrian SMEs. Journal of Small Business Management, 55(1), 108-127. https://doi.org/10.1111/jsbm.12248

Mulyaningsih, H. D. (2015). Enhancing innovation in quadruple helix perspective: The case of the business incubators in Indonesia. International Business Management, 9(4), 367-371.

Natário, M. M., Pedro Almeida Couto, J., \& Fernandes Roque de Almeida, C. (2012). The triple helix model and dynamics of innovation: a case study. Journal of Knowledge-Based Innovation in China, 4(1), 36-54. https://doi.org/10.1108/1756141121120875 8 
OECD, O. for E. C. and D. (2017). Enhancing The Contributions Of SMEs In A Global And Digitalised Economy (pp. 1-24). pp. 1-24.

OECD, O. for E. C. and D. -. (2020). Coronavirus ( COVID-19) ): SME Policy Responses.

Papadopoulos, T., Baltas, K. N., \& Balta, M. E. (2020). The use of digital technologies by small and medium enterprises during COVID-19: Implications for theory and practice. International Journal of Information Management, 55(Desember), 1-4.

https://doi.org/10.1016/j.ijinfomgt.2020.10 2192

Peng, M. W., Wang, D. Y. L., \& Jiang, Y. (2008). An institution-based view of international business strategy: a focus on emerging economies. Journal of International Business Studies, 39(5), 920-936. https://doi.org/10.1057/palgrave.jibs. 84003 77

Prajogo, D. I., \& Ahmed, P. K. (2006). Relationships between innovation stimulus, innovation capacity and innovation performance. $R \& D$ Management, 36(5), 499-515.

Pugh, R. (2014). The good, the bad and the ugly: Triple helix policies and programmes in Wales. Riple Helix Association Annual Conference.

PWS. (2020). UK economic update Covid-19.

Ranga, M., \& Garzik, L. (2015). From Mozart to Schumpeter: A Triple Helix System approach for enhancing innovation in the Salzburg region of Austria. In Austrian Council for Research and Technology Development (Ed.), Designing the future: economic, societal and political dimensions of innovation. Echomedia Buchverlag, Vienna.

Rao-Nicholson, R., Vorley, T., \& Khan, Z. (2017). Social innovation in emerging economies: A National systems of innovation based approach. Technological Forecasting \& Social Change, 121, 228237.

https://doi.org/10.1016/j.techfore.2017.03.0 13

Rapaccini, M., Saccani, N., Kowalkowski, C., Paiola, M., \& Adrodegari, F. (2020). Navigating disruptive crises through service-led growth : The impact of COVID19 on Italian manufacturing firms. Industrial Marketing Management, 88(May), 225-
237.

https://doi.org/10.1016/j.indmarman.2020.0 5.017

Roy, R., Lampert, C. M., \& Stoyneva, I. (2018). When dinosaurs fly: the role of firm capabilities in the "avianization" of incumbents during disruptive technological change. Strategic Entrepreneurship Journal, 12(2), 261-284. https://doi.org/10.1002/sej.1278

Sekaran, U., \& Bougie, R. (2013). Research methods for business: A Skill-building approach (6th ed.). John Wiley \& Sons, West Sussex.

Simo, G., \& Bies, A. (2007). The role of nonprofits in disaster response: An expanded model of cross-sector collaboration. Public Administration Review, 67, 125-142. https://doi.org/10.1111/j.15406210.2007.00821.x

Sudiana, K., Sule, E. T., Soemaryani, I., \& Yunizar, Y. (2020). The Development And Validation Of The Penta Helix Construct. Business: Theory and Practice, 21(1), 136145.

Tuunainen, J. (2002). Reconsidering the mode 2 and the triple helix: a critical comment based on a case study. Science Studies, 15(2), 3658.

Ucaktürk, A., Bekmezci, M., \& Ucaktürk, T. (2011). Prevailing during the periods of economical crisis and recession through business model innovation. Procedia Social and Behavioral Sciences, 24, 89-100. https://doi.org/10.1016/j.sbspro.2011.09.09 5

Ueasangkomsate, P., \& Jangkot, A. (2017). Enhancing the innovation of small and medium enterprises in food manufacturing through Triple Helix Agents. Kasetsart Journal of Social Sciences, 1-9. https://doi.org/10.1016/j.kjss.2017.12.007

Van Tulder, R., Seitanidi, M. M., Crane, A., \& Brammer, S. (2016). Enhancing the Impact of cross-sector partnerships four impact loops for channeling partnership studies. Journal of Business Ethics, 135(1), 1-17. https://doi.org/10.1007/s10551-015-2756-4

Wenzel, M., Stanske, S., \& Lieberman, M. B. (2020). Strategic responses to crisis. Strategic Management Journal, (March), $7-$ 18. https://doi.org/10.1002/smj.3161 